\section{Between fact and passion}

Alan Cottrell

No Immediate Danger: Prognosis for a Radioactive Earth. By Rosalie Bertell.

The Women's Press, 124 Shoreditch High Street, London E1 6JE: 1985.

Pp.435. Hbk £11.95; pbk£5.95.

Power Production: What are the Risks? By J.H. Fremlin.

Alan Hilger: 1985. Pp.318. £22.50, \$33.

How extraordinary it is that two such books as these, written by obviously sincere, intelligent, dedicated and independent authors on the same scientific subject -- the risks to the general public of nuclear radiation - should reach such diametrically opposite conclusions. The ground they cover, particularly the biomedical effects of radiation from nuclear power production, is virtually the same, although Dr Bertell's text extends to nuclear weapons production and testing, which she regards as inseparable from nuclear power, and Professor Fremlin's covers in some detail the risks from other methods of energy production, which are dealt with only cursorily and optimistically by $\mathrm{Dr}$ Bertell. The difference between the books is all the more extraordinary considering that, for both authors, the preservation of the natural world and its resources is a major objective, as is also the raising of the standard of living in the Third World. Furthermore, both see nuclear warfare as a total catastrophe for everyone. Yet, for Fremlin nuclear power is one of the few bright hopes for mankind on an overcrowded planet, whereas for Bertell it is an ultimate evil, to be attacked with the zeal of a crusader.

Fremlin's is a scientist's book. Cool analysis and numerical estimation are its weapons, used with great skill and elegance to expose many a foolish notion or false argument; for example, that $1 \mathrm{~kg}$ of plutonium would be sufficient to kill off all life on Earth. Thus

The natural uranium, radium and polonium in the ocean give off about 40 alpha particles per gram of sea-water per year. One kilogram of plutonium distributed in the oceans of the world . . . would give about 1 alpha particle per gram in 50,000 years [p.263].

In addition to his opposition to the unnecessary use of fossil fuels, Fremlin's main bias is "in favour of facts" and it is this that has led him to expose and attack false arguments used by anti-nuclear campaigners and disgracefully irresponsible treatments by the media, such as the blatant distortion presented by Yorkshire Television in Britain on 1 November 1983 (p. 275).

Dr Bertell is a scientist but hers is not a scientific book. It is a tirade and manifesto, brilliantly written, but with the set mind of the zealot. Passionate description and harrowing anecdote are her weapons, used with great skill and vividness to re- mind the reader of what must never be forgotten; of the immense horrors of Hiroshima and Nagasaki. But Bertell treats inconvenient facts more disdainfully than Fremlin. Thus, about the genetic effects of radiation she writes

the data accumulated at Hiroshima and Nagasaki did not give the desired answers. Either through ineptitude or loss of survivors of the bombing .... the researchers failed to find any severe genetic ills . . [ [p.47]

If the facts do not suit the argument, so much the worse for them! The passion also

IMAGE
UNAVAILABLE
FOR
COPYRIGHT
REASONS

Power of good? Part of the British Nuclear Fuels Sellafield site in Cumbria, UK.

leads to some surprising assertions. Thus, mankind's nuclear activities have caused acid rain (p.56), the change in the El Niño ocean current (p. 102), and earthquakes (p. 163), as well as 16 million casualties. It is all a conspiracy of militaristic governments, especially Western ones. Even Pearl Harbor was a tactic of the United States designed to strengthen the fighting attitude of American people (p.151).

In a sense, these two books re-enact the classical contest between heart and head in their attempts to find a better future for mankind. Bertell advocates the Utopian future of a global village in which

the fundamental human needs for food, shelter, clothing, medical care, education, work and social dignity are met, so that the tremendous human potential for creativity, art, science and culture is freed [p.295].

Magnificent, but is it not what mankind has always wanted? And how do we get it and maintain it? Bertell's answer is that

the money for food and celebration of life is being needlessly squandered on weapons and unneeded technological mega-projects [p.296].

Beating swords into ploughshares has been a desirable goal for endless generations and in each new one it has stumbled against the same old problem: human aggressiveness. This is why the heart is not enough. Its solutions are idealistic, planned for angels, not human beings. The head has also to play its part, to seek realism and practicality in the face of human nature as it stands. Peace with goodwill is what Bertell wants, but these may be beyond mankind's reach at present, in which case the grudging peace without goodwill that now exists between the nuclear superpowers may be the best that we can realistically have. But for Bertell, the concept of deterrence is simply not admitted; she is sure that the nuclear powers are preparing to go to war, not trying to dissuade each other from war, in spite of the fact that the European corner of the globe-traditionally a most belligerent region-has enjoyed an unprecedented period of freedom from war throughout the nuclear age.

Fremlin's goals are more limited but more attainable. The people of the world need energy. The big and rapidly multiplying poor in country villages in Africa and Asia need cooking fuel, clean water, practical education and time.

Kerosene and coal are alternatives to the destruction of the forests and the rich countries should be systematically planning to conserve these as effectively as possible and as soon as possible. Compared with the disastrous effects inevitable in an overcrowded world, none of the health hazards of any form of energy production are of any importance at all . .

The Third World can be helped in this respect

. if the richer countries use as much wind and solar energy as they can, develop nuclear energy . . . and use nuclear electricity to replace oil, coal and gas . . . [p.280].

Both books brilliantly expound their author's views but it seems likely that both will fail to persuade unsympathetic readers to change theirs. Fremlin's sophisticated rapiers, needle-sharp though they are, are unlikely to pierce the hermetic seals in which the anti-nuclear protesters have insulated themselves against contamination from uncongenial scientific facts. And the unrelieved damning of all things nuclear by Bertell appears too obsessive to be convincing. To this reader at least, the truth seems less likely to dwell among her passionate advocacies than among Fremlin's cool arithmetic.

Sir Alan Cottrell is Master of Jesus College, Cambridge CB5 $8 B L$, UK 